\title{
Oportunidad, conflicto y reconocimiento. El movimiento de trabajadores subcontratados de CODELCO y el Gobierno de Michelle Bachelet, 2006-2007
}

\section{Opportunity, conflict and recognition. Movement of Copper outsourced workers and the government of Michelle Bachelet, 2006-2007}

\author{
José Ignacio Ponce López*
}

\begin{abstract}
Resumen: Desde la teoría de la estructura de oportunidades políticas, se analiza el movimiento de trabajadores subcontratados de CODELCO y su relación con el Gobierno de Bachelet. Los cambios políticos y económico-sociales posibilitaron que esta acción colectiva de los trabajadores subcontratados irrumpiera y se instalara como un importante actor. Se trata de argumentar dicha tesis a través de fuentes cuantitativas y cualitativas, incluyendo técnicas de historia oral.
\end{abstract}

Palabras Clave: Movimiento sindical, subcontratación, Estructura de Oportunidades, estrategia de movilización de recursos.

\begin{abstract}
From the theory of the structure of political opportunities, it's analyzes the outsourced labor movement of CODELCO and its relationship with the government of Bachelet. The political and economic-social changes enabled that this collective action burst and install itself as a major actor. Try to argue this thesis through quantitative and qualitative sources, including oral history techniques.
\end{abstract}

Keywords: Labor movement, outsourcing, opportunity structure, resource mobilization strategy

Recibido: 2 de mayo 2016

Aceptado: 24 julio 2016

\footnotetext{
* Magister en Historia y Estudiante Doctorado en Historia, Facultad de Humanidades Universidad de Santiago de Chile. Este artículo fue producto de la tesis para optar al grado de Magister "Acción sindical durante los gobiernos de la Concertación. Los casos de las movilizaciones de Lota (1994-1997) y de Codelco (20052008).", financiada por la Beca para Estudiantes de posgrados del Centro de Estudio de Conflicto y Cohesión Social (COES), proyecto "CONICYT/FONDAP/15130009", y el proyecto "Fondecyt N ${ }^{\circ} 1150583$ ". Correo autor: jose.ponce.1@usach.cl
} 
José Ponce, Oportunidad, conflicto y reconocimiento. El movimiento de trabajadores subcontratados de CODELCO y el Gobierno de Michelle Bachelet, 2006-2007, Izquierdas, 29:106-132

\section{Introducción}

A contrapelo de lecturas que pudieran vincular mecánicamente la expansión de un sistema de precarización laboral y debilidad sindical, han sido los subcontratados, especialmente de la estatal Corporación nacional del Cobre, CODELCO, quienes se han convertido en un emblema para el resurgir del movimiento de trabajadores chileno en la última década. Tras irrumpir entre los años 2006 y 2007, este se ha proyectado hasta la actualidad en el país, su acción colectiva desarrolló una orgánica y se ha insertado en el escenario político nacional, manifestándose en su expansión hacia otros sectores de la minería, creando lazos con otros sectores de la sociedad y en las candidaturas parlamentarias de su principal líder, Cristián Cuevas (Jordana y Torres, 2013). Estos elementos, sumados a la instalación de una demanda histórica, como la Renacionalización del Cobre, los transformó en un sector referencial del movimiento de trabajadores chileno. Por ello, tal como un autor lo ha visto a partir del sindicalismo en el siglo XX (Garcés, 2012), el movimiento de trabajadores subcontratistas puede concebirse como uno de los principales movimientos sociales del país, susceptible de ser analizado desde alguna teoría desarrollada para comprender a éstos.

Los análisis sobre este movimiento, en general, se centraron poco en sus aspectos socio-políticos. Quienes se acercaron más a esto tratan de analizar el nivel interno de politización y sus formas de acción (Jordana y Torres, 2013) o en comparación con otros sector sindical similar (Jordana y Torres, 2009). Otros trataron de explicar la tensión entre precarización y movilización de estos sectores, sosteniendo que al alero de la subcontratación surgen emergentes y novedosos, aunque aún febles y muy abstractos, pero también muy permanentes y concretos, mecanismo identitarios de conciencia de clases y organización laboral (Agacino, 2001). En el caso de la minería, otro factor que fortaleció una identidad propia, es la percepción de diferencia en base a las desigualdades en las condiciones laborales, en las remuneraciones y beneficios sociales entre subcontratados y trabajadores de planta (Leiva, 2009). Llegándose a explicar el movimiento de subcontratados de CODELCO por la subjetividad identitaria al ser un sector marginado, precarizado y excluido de la bonanza económica producida por la cuprífera a mediados del 2000, en contraste con los trabajadores de planta más valorados (Castillo, 2011).

Con todo, para algunos autores, este movimiento sería parte de un nuevo ciclo en el sindicalismo chileno, donde los subcontratados juegan un rol protagónico. Sus movilizaciones manifestarían el surgimiento de un nuevo tipo de movimiento laboral (Villalobos, 2010), con nuevas líneas de acción, estratégias y liderazgos (Jordana y Torres, 2013; López, 2009). Para otros, específicamente sobre el movimiento de subcontratados de CODELCO, si bien consideran las características nuevas de los movimientos de trabajadores aparecidos el 2007, enfatizan en una mixtura de la nueva realidad y mecanismos de negociación, con formas de lucha que los mismos trabajadores consideran parte de un legado histórico del sindicalismo chileno (Amtmann, Barrera y Serra, 2011). Para otro autor, esta dialéctica entre continuidad y cambio, les permitió superar las esporádicas y frágiles formas de acción y organización que caracterizó a los trabajadores subcontratados hasta ese entonces (Núñez, 2009). Desde estos ángulos, creemos, se ha puesto más énfasis en la capacidad de acumular fuerza orgánico-política propia previamente al 2007, por parte de los subcontratados del cobre, lo cual habría sido el principal elemento explicativo de su irrupción, lo que ha llevado a denominar al nuevo "ciclo" que habría como el "renacer de la huelga obrera" (Aravena y Núñez, 2009) y/o 
José Ponce, Oportunidad, conflicto y reconocimiento. El movimiento de trabajadores subcontratados de CODELCO y el Gobierno de Michelle Bachelet, 2006-2007, Izquierdas, 29:106-132

como la crisis de la estrategia de subordinación de los trabajadores a la burguesía, a la derecha política y la Concertación (Aguiar, 2011).

El siguiente artículo pretende contribuir con una mirada distinta, que se nutre de la reflexión política de los movimientos sociales realizada por Sidney Tarrow (1997) para comprender el conflicto desatado por los trabajadores subcontratados de la cuprífera estatal. Aunque en el último tiempo el concepto se haya vuelto tan omnicomprensivo y amplio, al punto de generar muchas más confusiones que aclaraciones, tomaremos la perspectiva en su dimensión más coyuntural que de largo plazo (McAdam, McCarthy, Zald, 1999). Por ello, rescatamos la idea de que para proyectarse una acción colectiva son fundamentales "los cambios en la estructura de las oportunidades políticas (que) crean incentivos para las acciones colectivas. La magnitud y duración de las mismas dependen de la movilización de la gente a través de las redes sociales y en torno a símbolos identificables extraídos de marcos culturales de significado" (Tarrow, 1997: 25). Son estas modificaciones las que "originan nuevas oleadas de movimiento y dan forma a su despliegue", siendo "explotadas y expandidas por los movimientos sociales, transformados en acción colectiva y mantenidos por medio de estructura de movilización y marcos culturales" (Tarrow, 1997: 26-27). Pero la velocidad de estos cambios suelen ser rápidas y de breve extensión, teniendo "como resultado una represión inmediata, a veces la reforma y, con frecuencia, ambas cosas" (Tarrow, 1997: 28).

Siguiendo los planteamientos de Tarrow, consideramos para el caso estudiado siguientes indicadores evidencian variaciones en la estructura de oportunidades políticas: a) los desplazamientos al interior de los partidos políticos, lo cual generó nuevas correlaciones, especialmente en el gobierno de Michelle Bachelet; b) esto posibilitó nuevos equilibrios y disputas en la elite política, manifestándose entre otras cosas en las elecciones presidenciales del 2005-2006; c) la aparición de nuevas realidades laborales precarias donde la estrategia de concertación social no era la hegemónica; d) una opinión pública más atenta a la realidad de la minería cuprífera dado el "boom" del metal rojo, donde se generó un debate sobre el aporte de esta industria al país, lo que contrastaba con la extensión de la precarización laboral en su producción; e) una mayor sensibilidad entre los actores políticos y la opinión pública en torno a realizar cambios y nuevas regulaciones en las condiciones de trabajo, particularmente de la subcontratación; f) el despliegue de una oleada de movilización social que evidenció la capacidad de las formas de acción colectiva y los posibles logros a través de la presión; g) la disposición del régimen político a la represión de dichas manifestaciones, lo cual terminó con la muerte de un trabajador contratista forestal, pero que a la postre obligó a las empresas a generar concesiones que incluso iban más allá de la legislación con los trabajadores movilizados. El conjunto de estas variables, creemos, posibilitaron el desarrollo de una ventana de oportunidades políticas que los trabajadores subcontratados del cobre podían utilizar en su favor.

Desde esta óptica, no queremos rechazar de plano las tesis donde los trabajadores subcontratados de CODELCO fueron capaces de aprovechar un momento político para presionar con toda su fuerza y convertirse en un actor relevante, sino que para posibilitarse esta irrupción, tuvieron que darse otros factores que modificaron y reacomodaron algunos aspectos de la dimensión política del Estado, pero también cambios en la estructura social del país. Esto requiere ensamblar la organización y repertorio de acciones del movimiento, con las transformaciones en el contexto socio-político del país, relacionándolo así con los 
José Ponce, Oportunidad, conflicto y reconocimiento. El movimiento de trabajadores subcontratados de CODELCO y el Gobierno de Michelle Bachelet, 2006-2007, Izquierdas, 29:106-132

posicionamientos de otros actores, especialmente de la contraparte de este movimiento: CODELCO y el gobierno de Michelle Bachelet.

Sostenemos que el movimiento de subcontratados del Cobre sedimentó, al menos por un lustro, un proceso de organización y articulación sindical que hizo sus primeras apariciones el año 2005, pero irrumpió con fuerza el año 2007. Su accionar se desarrolló a través de una compleja trama de acciones que presionaban y usaban parte de la institucionalidad, principalmente en base a la legislación aprobada el año 2006 y las alianzas informales o redes con actores que ya eran parte del aparato estatal. Todo ello tenía por objetivo primordial que los reconocieran como un actor sindical a escala nacional, especialmente como un interlocutor válido de CODELCO. Cuestión que lograron tras la movilización del año 2007. Sin embargo, este triunfo político de corto plazo, estuvo limitado como precedente para la negociación sectorial (que era su segundo gran objetivo) por la fórmula de acuerdo implementada por la empresa estatal.

Esta inicial irrupción triunfante, estuvo posibilitada por la carencia de una estrategia hegemónica de neutralización o de negociación del gobierno con el mundo subcontratado, que le había funcionado con otros sectores del sindicalismo chileno años atrás. Con el agotamiento de la coalición gubernamental y el recambio presidencial, junto con la aparición de este movimiento entre los años 2006-2007, cobró más fuerza al interior del gobierno de Michelle Bachelet un sector proclive a la regulación de las relaciones laborales y el reconocimiento del sindicalismo subcontratado, cuestión que tensionó a los sectores más liberales y pro empresarial del nuevo gobierno. Aunque este último hegemonizó la postura inicial del Ejecutivo, pues controlaban los principales cargos de CODELCO, dada la fuerza y cohesión del movimiento subcontratado, y su revuelo político nacional alcanzado, terminó por implementarse de facto la posición del sector que buscaba el diálogo hacia el mundo sindical subcontratado, siendo quienes apoyaron una compleja salida al conflicto, donde el gobierno minimizó sus costos políticos y CODELCO legalmente no apareció involucrada directamente en el conflicto. El rol público mediador jugado por la Iglesia, fue funcional a esta estrategia.

Consideramos que este caso particular, nos permite comprender que las transformaciones laborales experimentadas en el país bajo los gobiernos de la Concertación, terminó por tensionar su estrategia de negociación que subordinaba de forma predefinida al movimiento laboral, cuestión que utilizó durante el periodo anterior con el sindicalismo tradicional.

La investigación se basó principalmente en fuentes de tipo cualitativas. Además de la bibliografía sobre los temas vinculados a la problemática analizada, la prensa de la época nos sirvió para construir en detalle el proceso de movilización y las posiciones de los actores involucrados. Para acercarnos a las miradas de actores claves, como los dirigentes subcontratistas, se recurrió a entrevistas realizadas por otras investigaciones ${ }^{1}$, y para acercarnos a una mirada de gobierno, entrevistamos al por entonces ministro del trabajo, Osvaldo Andrade (2013). También usamos fuentes de orden cuantitativo desarrolladas por organismos de gobierno para dar cuenta de algunas realidades económico-laborales.

\footnotetext{
${ }^{1}$ Acá agradecemos a María Loreto Serra por facilitarnos los anexos de su tesis de pregrado, donde aparecen las entrevistas a Cristian Cuevas (2011), Jorge Peña (2011) y Manuela Ahumada (2011), en el marco del trabajo realizado entre Amtmann, Barrera y Serra (2011).
} 
José Ponce, Oportunidad, conflicto y reconocimiento. El movimiento de trabajadores subcontratados de CODELCO y el Gobierno de Michelle Bachelet, 2006-2007, Izquierdas, 29:106-132

El artículo se estructura en cinco apartados: a) el primero esboza los cambios en la estructura de oportunidades políticas a nivel institucional y al interior del movimiento sindical; b) después se da cuenta de la importancia que adquirieron la industria cuprífera y el problema de la subcontratación a nivel nacional; c) posteriormente se analizan los procesos de organización y lucha previos al conflicto del 2007 por parte de los trabajadores subcontratados; d) se continúa con una pormenorizada revisión del conflicto del año 2007; y e) se termina exponiendo la salida del conflicto. Finalizamos con una breve conclusión en torno a la investigación realizada.

\section{1) Gobiernos Concertacionistas y movimiento sindical: la "transición" de los trabajadores y los cambios en la estructura de oportunidades políticas.}

Entre los debates que buscan hacer un balance sobre los gobiernos de la Concertación, están quienes, aunque no niegan la capacidad de esta coalición política para introducir cambios a la realidad chilena, enfatizan los elementos de continuidad del sistema económico, social y político implementados en la Dictadura, por lo que los gobiernos posdictatoriales habrían consolidado el modelo neoliberal (Moulian 1998; Claude, 2006; Fazio y Parada, 2010; Gómez, 2010; Mayol, 2011). Otros, han enfatizado las transformaciones impulsadas por estos gobiernos, llegando a hablar del "modelo concertacionista", en oposición al instalado bajo el régimen de Pinochet (Hunneus, 2000; Muñoz, 2006; Hidalgo, 2011; Varas, 2012). Últimamente han aparecido visiones intermedias, que incluso apoyando la tesis de la continuidad, sostienen que en definitiva también existieron algunos cambios relevantes, aunque limitados (Garretón, 2012). Un estudio reciente, nos plantea que si bien los gobiernos de la Concertación se basaron en una premisa que asumía una relación intermedia entre imposición dictatorial y pacto transicional, que prevaleció hasta el gobierno de Lagos, dicho supuesto comenzó a experimentar una descomposición desde el 2005, que se expresó en la promulgación de las reformas constitucionales. Esto porque había cambiado la estructura de intereses de los mismos actores, cuestión que los llevó a actuar de forma distinta (Fuentes, 2012).

Estas ideas nos dan luces para una interpretación propia de los gobiernos concertacionistas. Tal como sostienen algunos autores, es indudable que el significado histórico de los gobiernos concertacionistas fue de consolidación y legitimación del modelo socio-económico y político instalado en la Dictadura, el cual necesitaba para proyectar su gobernabilidad, inclusión social y mayor regulación de sus dinámicas económicas, por tanto necesitaba algunas correcciones, como sugiere Garretón (2012), pero no reformulaciones sustanciales. Quizás el problema laboral sea, como veremos, el que más evidenció esto. Pero también, cabe sumar la lógica que nos plantea Fuentes (2012): es decir, las correcciones políticas que se llevaron a cabo para proyectar el modelo por más tiempo, si bien lo han mantenido por un periodo no menor, sin quererlo también fueron erosionando algunas de sus dimensiones, lo que se sumó al intento por cambiar las correlaciones y estrategias políticas de los principales actores que maniobraban al interior de la institucionalidad. Esto permite integrar las siempre complejas, y a veces contradictorias, variables entre continuidad y cambio que finalmente operaron durante los gobiernos de la Concertación. Con ello se fue constituyendo un Chile que tenía como 
José Ponce, Oportunidad, conflicto y reconocimiento. El movimiento de trabajadores subcontratados de CODELCO y el Gobierno de Michelle Bachelet, 2006-2007, Izquierdas, 29:106-132

"unidad de sentido" las lógicas neoliberales, siendo posible concebirla como una "sociedad neoliberal" (Gómez, 2010), pero que incluye un mosaico de fenómenos que matizan y anclan dicho fenómeno en una realidad más compleja, donde coexisten distintas formas de socialización que cuestionan dicha "matriz neoliberal" dominante, aunque con un carácter fragmentario (Araujo y Martuccelli, 2012).

Con todo, la mantención de los pilares del modelo dictatorial tenía como elemento fundamental la continuidad de sus relaciones laborales. El rol jugado por el movimiento de trabajadores y las transformaciones impulsadas en el mundo laboral durante los gobiernos concertacionistas son importantes para comprender lo ocurrido en el Chile posdictatorial. Sobre este tema existe casi un consenso al interior de las ciencias sociales sobre la debilidad del sindicalismo chileno en comparación con periodos anteriores. Son distintos los factores que habrían incidido en esto. Los cambios estructurales como la globalización generaron una nueva realidad para los trabajadores (Drake, 2000), en torno a la que el sindicalismo fue incapaz de adecuarse (Frías, 2008). Estas transformaciones golpearon las bases objetivas y subjetivas del movimiento laboral, posibilitando su desarticulación como sujeto, situación aprovechada por las corrientes proclives a la concertación social y política a inicio de los noventa (Agacino, 2001). La ingeniería política aplicada desde los gobiernos de Aylwin y Frei debilitó aún más al movimiento sindical (De la Maza, 1999). Unido esto a la acción empresarial y de la derecha política por bloquear distintas reformas laborales planteadas desde la Concertación, impidiendo mejorar las condiciones del sindicalismo (Henriquez, 1999). En este marco, una de las principales debilidades del movimiento de trabajadores fue la subordinación al sistema político partidista y socioeconómico imperante (Ferres, 2009). Esto explicaría que incluso tras las reformas laborales concertacionistas, no obstante realizar cambios en justicia, fiscalización y regulación laboral, la posición de poder e influencia de los sindicatos quedó legalmente igual, es decir, muy debilitada (Aravena y Núñez, 2011).

Con este marco socio-político, en Chile se expandió un fenómeno del trabajo en la última década del siglo XX y la primera del XXI: la subcontratación ${ }^{2}$. Dentro de las causas de su masificación sería la promoción abierta de las empresas, pero también por su acción soterrada para disimular y evadir problemas o la legislación laboral y/o tributaria, externalizando así también los conflictos laborales (Echeverría, 2010). Por eso, incluso cuando se avanzó en regular la relación entre instituciones vinculadas a la subcontratación el año 2006, la mantención de ésta terminó favoreciéndola, pues no atacó sus principales problemas laborales y fuentes de origen (Figueroa, 2008).

Lo importante para este trabajo es que esta nueva realidad en expansión manifestó a la postre un cambio cuantitativo y cualitativo de la situación laboral chilena, y vino a poner en tensión los rasgos de lo que podríamos llamar la "transición" laboral, es decir, las lógicas políticas de concertación social hacia el sindicalismo. Tras ser una consecuencia de los tiempos del "pacto" transicional, la subcontratación al ser cada vez más hegemónica puso en cuestión esa estrategia política para subordinar la clase trabajadora al empresariado (Aguiar, 2011), ya que hizo emerger nuevos actores, en este caso, las diversas expresiones de los trabajadores subcontratados. Desde esta óptica, se puede comprender la irrupción de los subcontratados el año 2007, la relevancia que alcanzaron y sus principales objetivos en

\footnotetext{
${ }^{2}$ Un análisis descriptivo-legal del fenómeno en Ugarte (2009).
} 
José Ponce, Oportunidad, conflicto y reconocimiento. El movimiento de trabajadores subcontratados de CODELCO y el Gobierno de Michelle Bachelet, 2006-2007, Izquierdas, 29:106-132

esos años: el reconocimiento político, sea de facto o legal, como un actor relevante del mundo laboral chileno.

2) La dimensión socioeconómica de la estructura de oportunidades para el movimiento de subcontratados de CODELCO: La posición estratégica.

En los aspectos claves de la economía chilena y en el mercado de trabajo se producen cambios sustanciales que fueron el "telón de fondo", o lo que podríamos llamar las "estructuras de oportunidades materiales" para una irrupción de la magnitud política que tuvo la movilización de los subcontratados de CODELCO el 2007.

Históricamente, la minería cuprífera ha jugado un rol fundamental en la economía chilena. Sin embargo, durante los gobiernos de la Concertación ésta tuvo vaivenes en su proporción de participación en el PIB. Por un lado, desde el 2003 evidencia una tendencia hacia un leve decrecimiento desde un $7 \%$ a un $6 \%$. Si bien esto parece un porcentaje menor, para ser solo un producto de la canasta de exportaciones y producción de un país es considerable. Más aún cuando su participación en las exportaciones aumenta de manera sustancial, de un 40\% en el 2003 a un pick del 60\% en 2007 (COCHILCO, 2013). De tal manera, durante el ciclo de movilizaciones que analizamos, el cobre vive una creciente relevancia en la economía chilena, reflejada en el salto que da en su proporción al interior de la minería, donde llega casi al 90\% de las exportaciones en este rubro durante el 20062007. En estos años se vivió el boom de la minería cuprífera nacional (Fazio y Parada, 2010). Lo que en el marco de una economía marcada por un carácter principalmente exportador de materias primas, convertía a la industria cuprífera en un área estratégica del esquema productivo nacional.

Pero durante los gobiernos de la Concertación se dio una capitalización privada de los nuevos yacimientos cupríferos (Fazio y Parada, 2010). De allí que el porcentaje de producción representado por CODELCO, en comparación al total de empresas productoras de Cobre, hacia el 2005-2007 fuese de solo un tercio. Por tanto, gran parte de las ganancias por las exportaciones de este mineral se la llevó la minería privada (Lorca y Núñez, 2012). Ahora, el aporte de CODELCO a las arcas fiscales siguió siendo sustancial, llegando al $22 \%$ el 2006, el mayor porcentaje desde 1989 (COCHILCO, 2013). En síntesis, la producción chilena de cobre vivía uno de sus mejores momentos hacia el 2005-2007 (Fazio y Parada, 2010).

El impacto de estas tendencias en la economía nacional fue tal que bajo el Gobierno de Lagos y de Bachelet se instaló una serie de debates sobre distintas transformaciones que debía experimentar el cobre para su mejor desarrollo y contribución al país. En efecto, la inexistencia de una política cuprífera en el primer gobierno chileno del siglo XXI, fue obligada a abrir debates sobre la eficacia de CODELCO y la contribución impositiva de la minería privada, en torno a los llamados Royalties (Latorre, 2005). La centralidad política de estos debates llevó a que Michelle Bachelet incluyera en su programa de gobierno una política minera específica, que aun cuando no cambiara los principales aspectos de la industria, si clarificaba que las empresas estatales no serían privatizadas, a diferencia de cierta ambigüedad que se venían instalando en los gobiernos previos (Lorca y Núñez, 2012). 
José Ponce, Oportunidad, conflicto y reconocimiento. El movimiento de trabajadores subcontratados de CODELCO y el Gobierno de Michelle Bachelet, 2006-2007, Izquierdas, 29:106-132

Esta situación de la economía chilena en general y de la minería cuprífera en particular, iba acompañada por una creciente flexibilización de las relaciones laborales del país. La subcontratación fue una de sus principales expresiones. Un barómetro de esta situación, como la Encuesta Laboral (Encla, 2005), señalaba que la mitad de las empresas analizadas subcontrataba, donde las medianas y grandes empresas superaban el $65 \%$ hacia el 2005. Lo que se estimaba para esta época desde el Ministerio del Trabajo, es que a nivel general de la economía un 35\% de la fuerza laboral provenía de la subcontratación o del suministro de trabajo. La minería era el segundo sector donde más se repetía esta realidad, con más de un $60 \%$ de trabajadores subcontratados hacia el 2004. Siendo CODELCO una de las principales promotoras, pues llegó al 2006 con un 63\% de trabajadores: 30.000 subcontratados versus 17.000 trabajadores de planta (Silva, 2007). Vemos así una masificación creciente de la subcontratación en la economía chilena, especialmente en la minería y CODELCO. Esto no era menos relevante para la movilización de los subcontratados de la estatal, pues esta situación socio-económica fue una condición de posibilidad más para que estos trabajadores sensibilizaran a la opinión pública y generaran una identificación con el resto de la población por su condición laboral.

Las transformaciones estructurales mencionadas, es decir, el posicionamiento estratégico de la industria cuprífera y la masificación de los trabajadores del cobre, otorgaron ciertas posibilidades fundamentales para los subcontratados. Por un lado, siguiendo el planteamiento de Womack Jr. (2007), la masificación de los subcontratados en la principal empresa minera del país, que le daba importantes recursos al fisco, le había entregado una potencialidad disruptiva a su fuerza que podía generar un remezón político bastante importante. Por otro, la expansión generalizada de la figura del subcontrato facilitó que los mineros pudieran tener una dimensión con la cual identificarse con otros actores laborales ciudadanos. Ambos elementos, sumados al debate sobre el aporte del cobre a la sociedad chilena, configuraron un ambiente propicio para la movilización, que al cruzarse con los anteriormente esbozados reacomodos políticos en el escenario nacional, posibilitaron un resurgimiento de la acción sindical en el mundo cuprífero.

\section{3) Acumulación de fuerza previa de los subcontratados de CODELCO.}

Pero para explicar este movimiento no se puede desconocer la organización y experiencia acumulada por los subcontratados de CODELCO desde el 2003 en adelante. Como cuenta Cristián Cuevas, los subcontratados de la empresa estatal venían "desde fines de los noventa tratando de articular un movimiento, pero no lograba hacer una síntesis. Y después de un esfuerzo colectivo, de distintas orgánicas sindicales, fuimos generando una plataforma común para el sector de los trabajadores mineros, o de la minería, que prestan servicios en CODELCO" (Cuevas, 2011).

Para lograr esa articulación que relata Cuevas, se debían fortalecer algunos sindicatos que ya existían, destacando aquí el rol del Sindicato Interempresa de la Gran Minería y Ramas Anexas (SITECO). Éste fue uno de los primeros en alzar la voz de los subcontratados a finales de los ochenta, pero se había debilitado en los noventa, por lo que para revertir esta situación, un dirigente ha afirmado que "desde el 2002 nos juntamos un grupo de dirigentes y nos propusimos levantar el sindicato y empezar a luchar. Y junto con hacer crecer el sindicato, o sea meterle socios y empezar a discutir una plataforma mínima 
José Ponce, Oportunidad, conflicto y reconocimiento. El movimiento de trabajadores subcontratados de CODELCO y el Gobierno de Michelle Bachelet, 2006-2007, Izquierdas, 29:106-132

de lucha, vimos la necesidad también de coordinarnos con sindicatos de otras divisiones de CODELCO: de Andina, del Salvador o de Calama" (Peña, 2011).

El carácter interempresas del SITECO le permitió aglutinar a pequeños grupos de trabajadores que pertenecían a distintas empresas contratistas. Su crecimiento respondió a una estrategia planificada: "lo que nosotros hicimos primero fue meternos a organizar y afiliar trabajadores en estas empresas, donde las dotaciones de trabajadores fueran superiores a trescientas o doscientas, para hacer número" (Peña, 2011). Tuvo como demandas iniciales: "el pago de horas extraordinarias, contratos más largos para tener derecho a vacaciones e indemnización por años de servicio, y pelear por un tarifado nacional de sueldo. Esa fue como la invitación que se les hizo a los trabajadores... iy pescaron! Los trabajadores engancharon" (Peña, 2011). Fue este sindicato quien hacia el 2003 y tras obtener pequeñas mejoras laborales, realizan la primera demanda de los subcontratados por una negociación colectiva, llegando a la toma de la mina El Teniente, lo que terminó en "una fuerte represión por parte de CODELCO, que incluso en este caso, Danilo Jorquera, que era el líder de este movimiento de los subcontratados, es acusado por la Ley de Seguridad del Estado; y es reprimido violentamente ese movimiento en diciembre del 2003, que costó el despido de decenas de trabajadores, de heridos" (Cuevas, 2011). Llevándolos a pensar que "era muy difícil lograr articular un movimiento en la División con ese estado de represión" (Ahumada, 2011). No obstante esta derrota, el SITECO en el 2004 alcanzó a aglutinar 6.000 trabajadores, además de haber adquirido experiencia de lucha y algunas pequeñas mejoras laborales. Por tanto, la experiencia de lucha había ayudado a sumar afiliados.

Otro elemento de esta experiencia de lucha habían sido los mecanismos de negociación colectiva de facto que desarrolló el SITECO con la división el Teniente de CODELCO. Estos fueron los llamados "protocolos de acuerdo", una alternativa a contratos o convenios colectivos, que se materializaban a través de dos vías: a) los sindicatos por empresas contratistas negociaban como grupo, donde el SITECO los asesoraban para conseguir algunas regalías, tales como aumento de sueldo; b) pero para cuestiones "standard" y transversales, tales como la extensión mínima de contratos, el pago de horas extras, vacaciones e indemnizaciones para todos los trabajadores, el SITECO negociaba con CODELCO. Esta última dimensión era entendida por los trabajadores como la negociación de "verdad" (Peña, 2011).

En el marco de estas distintas luchas con avances y retroceso, los subcontratados fueron proyectando la idea de una articulación nacional. Es así que "el sindicado impulsa el Primer Encuentro de Trabajadores Contratistas, que se realizó el 2003 en Rancagua" (Peña, 2011). Donde salvo Ventana, participan las restantes divisiones de CODELCO ${ }^{3}$, pero que no logran concretarse por diferencias políticas y críticas que se realizaban en algunos sindicatos de la división Norte a la militancia comunista de gran parte de los dirigentes participantes: "luego, al año siguiente, hubo un encuentro en Calama, para lo mismo, y por la misma razón, como ahí los del norte eran anfitriones, fracasó” (Peña, 2011). Finalmente, tras "una decisión política, pensada, planificada" (Cuevas, 2011) se desarrollan otros encuentros "en Antofagasta y en Diego de Almagro. El último es el de Caldera, ese fue el

\footnotetext{
${ }^{3}$ La empresa está compuesta por 4 divisiones: Codelco-Norte (Calama y el Salvador), Codelco-Ventanas, Codelco-Andina y Codelco-El Teniente.
} 
José Ponce, Oportunidad, conflicto y reconocimiento. El movimiento de trabajadores subcontratados de CODELCO y el Gobierno de Michelle Bachelet, 2006-2007, Izquierdas, 29:106-132

2006" (Peña, 2011) para concretar una plataforma nacional de trabajadores subcontratados del cobre.

Este proceso decantó el año 2005 en la Coordinadora de Trabajadores Contratistas, que era institucional y orgánicamente precaria, donde muchos dirigentes eran muy jóvenes e inexpertos. Su primera gran actividad fue la entrega de un pliego de demandas en las distintas divisiones de CODELCO el 21 de diciembre del 2005, entre la primera y segunda vuelta presidencial de Chile que enfrento a Michelle Bachelet y Sebastián Piñera. CODELCO respondió negativamente a ellas, llevando a los subcontratados a impulsar una primera movilización que fuera más allá de una división, logrando "movilizar El Teniente, Andina, algunas manifestaciones en Ventanas, manifestaciones y marchas en Calama" (Ahumada, 2011). Esta movilización terminó en una huelga el 4 de enero del 2006, que tuvo expresión real en los Andes y Rancagua. Dado el contexto, los subcontratados se reunieron con Piñera y Bachelet, estableciendo compromisos para que en un eventual gobierno respondieran a sus demandas. Sólo después de 20 días de huelga, el 7 de febrero, "se firman las Actas de Acuerdo entre CODELCO, nosotros, y las contratistas. Pero lo principal es que CODELCO firma un documento" (Cuevas, 2011). Cabe precisar que estos acuerdos se firman a nivel de divisiones y no nacional, por lo que el principal triunfo fue un reconocimiento político incipiente de CODELCO a la Coordinadora, sentando un precedente para las futuras acciones de los subcontratados. No fueron menos importante la irrupción mediática que tuvieron estos últimos en el marco del debate político-presidencial nacional en el cual se desarrolló, donde se reinstaló el tema de la subcontratación, y la no menos importante mantención de todos los trabajadores movilizados, incluyendo el pago de todos los días de paro.

Pero, tal como reconociera Jorge Peña, “en el 2005 y 2006, en El Teniente, CODELCO nos impuso como uno de los garantes a Raimundo Espinoza, el presidente de la FTC" (Peña, 2011). Este punto es importante para entender el inicio de las tensiones con la Federación de Trabajadores del Cobre, donde se aglutinan quienes tienen contratos de planta y está encabezada por el socialista Raimundo Espinoza, que en su calidad de Presidente de la FTC es parte del Directorio de CODELCO. Así, este representaba tanto los intereses de los trabajadores de planta como los de la empresa, por lo mismo, desmarcarse de él era vital para los subcontratados, tanto para convertirse en interlocutores válidos como para hacer valer el cumplimiento de sus intereses autónomamente de la empresa.

La repercusión política de este movimiento fue tal que el gobierno de Lagos le puso urgencia a la aprobación de la Ley de Subcontratación, que llevaba varios años estancada en el parlamento. Como ha señalado Rolando Álvarez (2009), esta legislación fue una "ley para hacer cumplir la ley". El mismo autor detalla tres variables que permitieron lograr su promulgación: a) un discurso consensuado en la clase política sobre la inequidad laboral; b) con el nuevo gobierno de Bachelet, aparece un empoderado Ministro del Trabajo, cuestión que no había pasado en los gobiernos concertacionistas previos; c) la serie de movilizaciones sociales que se dieron el año 2006, donde despuntó la llamada "revolución pingüina" de los estudiantes secundarios. Según Álvarez, estos factores incidieron para que se reinstalara en el debate público el tema de la subcontratación y se promulgara la Ley en octubre del 2006. Es interesante la afirmación de Álvarez en torno a que la Concertación tenía la mayoría parlamentaria para aprobar el proyecto de Ley sin negociar con la Derecha, cuestión que podría haber generado importantes cambios en materia laboral. Sin embargo, gracias a las presiones del empresariado y las diferencias al interior del gabinete, se 
José Ponce, Oportunidad, conflicto y reconocimiento. El movimiento de trabajadores subcontratados de CODELCO y el Gobierno de Michelle Bachelet, 2006-2007, Izquierdas, 29:106-132

privilegió un acuerdo con la oposición. Además, algunos cambios importantes como el concepto de empresa, finalmente la Derecha judicializó su resolución y terminó derrotando a los sectores "progresistas" del gobierno, al ser rechazada dicha idea en el Tribunal Constitucional (Álvarez, 2009). Esto evidencia, que si bien se instaló un contexto político y gubernamental más óptimo para los trabajadores, existían actores sociales, políticos y judiciales que serían un duro escollo para ellos.

Fuera del Congreso, los subcontratados de CODELCO le comenzaron a exigir el cumplimiento de los acuerdos firmados en la campaña presidencial a Bachelet. Paralelamente a estas apariciones públicas, impulsan un proceso de estructuración mayor, generando el primer Congreso Oficial de la Coordinadora en abril del 2006.

$\mathrm{Su}$ presión al gobierno da frutos, pues por mandato del Ejecutivo se establecen mesas tripartitas (CODELCO, empresas contratistas y trabajadores) entre abril y agosto del 2006 en cada una de las divisiones de CODELCO. Aunque sin rendir muchos resultados materiales, para los dirigentes de los subcontratado "a raíz de estas mesas permanentes... se empieza a construir un petitorio más concreto, donde se empieza a pedir cuestiones" (Ahumada, 2011). Esto se materializó en demandas por ampliar a los subcontratados algunos beneficios sociales y laborales que ostentaban los trabajadores de planta, como también del reconocimiento de su rol productivo a través de bonificaciones.

Aunque en el 2006 se promulgó la Ley de Subcontratación y se instalaron las mesas de diálogo tripartitas por división en CODELCO, los trabajadores sentían que la cuprífera y el gobierno dilataban una respuesta favorable a sus demandas. Esto los llevó a nuevos emplazamientos públicos a la Presidenta, el más relevante fue cuando entró en vigencia la Ley de Subcontratación en enero del 2007, momento en que Cristián Cuevas le entrega las actas de acuerdo con CODELCO a Bachelet, la cual se comprometió a reanudar las mesas de trabajo que se extendieron entre marzo y junio del 2007 (Cuevas, 2011).

En este marco, durante los primeros días de mayo del 2007, en el sur de Chile ocurre un hecho fundamental para el movimiento de trabajadores subcontratados. El mes que históricamente ha movilizado a los trabajadores del país, comenzó con la huelga de los forestales de Bosques Arauco. Esta movilización que articulaba a distintos sindicatos de empresas contratistas de la forestal, alcanzó gran revuelo a los pocos días de iniciarse (30 de abril) por un hecho fatal: el asesinato por parte de carabineros del trabajador Rodrigo Cisternas. Este hecho causo conmoción y movilizó a gente en todo el país (Osal 05/2007). Volvió a instalarse así una opinión pública contra el abuso a los trabajadores, donde actores como la Iglesia se mostraban a favor de una pronta solución del conflicto. Ante este panorama, la empresa mandante inicio las conversaciones con los movilizados y llegó a un acuerdo el 8 de mayo, donde si bien las empresas contratistas y los trabajadores subcontratados firmaron el acta, públicamente se reconoció que Bosques Arauco se haría cargo de la negociación (Ruminot, 2009). De tal manera, los forestales forzaron a la patronal a una negociación colectiva interempresa pero con la empresa mandante incluida.

Este acontecimiento inició un agitado ciclo laboral, donde los subcontratados fueron su principal expresión. Como pocas veces desde el inicio de la "transición" un sector de trabajadores logró instalarse como actor relevante en el escenario político nacional, siendo capaces de doblegar a otros actores y aprovechar coyunturas propicias para instalar sus demandas, de allí que se hablara en un momento del renacer de la huelga obrero (Aravena y Núñez, 2009). De esto rescatamos que se generó un ambiente-coyuntura propicio para los 
José Ponce, Oportunidad, conflicto y reconocimiento. El movimiento de trabajadores subcontratados de CODELCO y el Gobierno de Michelle Bachelet, 2006-2007, Izquierdas, 29:106-132

trabajadores y altamente sensible a sus demandas (Álvarez, 2009), donde la apertura de un nuevo "ciclo" de acción sindical era una posibilidad, pero que debía ser disputada.

\section{4) Trabajadores, gobierno y otros. Objetivos y estrategias durante la movilización del 2007.}

Con este ambiente, hacia junio del 2007 los subcontratados veían que nuevamente una resolución a sus demandas era dilatada en las mesas tripartitas impulsadas por el gobierno. Cuestión agudizada tras restarse este último de las conversaciones, argumentando que se los trabajadores pedían temas salariales no contemplados en la nueva ley, dejando la resolución del conflicto a CODELCO, las contratistas y los trabajadores (La Nación 27/06/2007). Esta situación se cruza con la decisión final de los subcontratados de CODELCO por constituirse en la "Confederación de Trabajadores del Cobre, el 8 de junio.... Y en eso, como CODELCO no quería cumplir los acuerdos, o los relativizaba, en ese Congreso nosotros decidimos convocar a la primera huelga general de trabajadores contratistas" (Cuevas, 2011). Tomando como legitimación los convenios internacionales para darle un tinte legal a sus acciones, pretendían movilizarse con el objetivo de "fortalecer la negociación por rama... que ya habían comenzado también los forestales." (Peña, 2011).

Un obstáculo importante era la dinámica de la movilización, pues la experiencia indicaba a los dirigentes que "CODELCO se preparaba con toda la repre[sión], y el inicio de la huelga podía sufrir alteraciones y fracasar. O sea, hacernos fracasar la movilización" (Peña, 2011). Por lo que el "factor sorpresa" era fundamental para empezar: "todo el mundo sabía que estaba declarada la huelga, pero nadie sabía cuándo comenzaba" (Peña, 2011). Esto los llevó a operar herméticamente, pues sólo Cristián Cuevas, por entonces recién electo presidente de la CTC, y un par de dirigentes sabían de antemano el día y la hora de la movilización. Pocos días antes se enteraría otro grupo, pero la gran mayoría de trabajadores lo haría al amanecer de la misma jornada de movilización (Cuevas, 2011).

Otro elemento fundamental para la nueva organización si se quería consolidar, era la extensión y desgaste de una huelga. Como ha relatado Cuevas, esta preparación "llevó a que el trazado inicial de la huelga fuera breve", pensando que con dar un sólo golpe, a lo más en tres o cuatro días, CODELCO se sentaría a negociar (Cuevas, 2011).

Estos elementos parecían marchar de acuerdo a lo planificado por los subcontratados, pues a las 08:00 de la mañana, en los Andes, Rancagua y Calama tenían "controlada toda la industria" (Cuevas, 2011). Pero el gobierno estaba moviendo sus propias fichas, quien aunque no sabía el día exacto, debía prepararse políticamente para sus repercusiones. Las preocupaciones del Ejecutivo, como nos relata el entonces Ministro del Trabajo, Osvaldo Andrade, eran:

uno, la radicalidad que asumiera esta movilización, no solo porque se trata de la empresa más importante del país, sino que además porque tiene representación territorial en distintos lados, entonces tiene una connotación pública inevitable. Segundo, que se produjeran enfrentamientos entre los trabajadores de planta y subcontratados, y la preocupación fundamentalmente tenía que ver con una clara disparidad desde el punto de la trayectoria y en el peso específico entre uno y otro. En tercer lugar, era que el empresario subcontratista no pasara piola 
José Ponce, Oportunidad, conflicto y reconocimiento. El movimiento de trabajadores subcontratados de CODELCO y el Gobierno de Michelle Bachelet, 2006-2007, Izquierdas, 29:106-132

también, porque si nosotros teníamos nociones de cadenas productivas de que habían 10, 11, 12, 15, 17 subcontratos, entonces claramente ahí había un proceso también de exageración y abuso de la forma de organización del sistema productivo que evidentemente no contaba con el respaldo del gobierno, pero era una realidad... (Andrade, 2013)

Pero esta postura que pretendía reabrir las conversaciones no era única del gobierno, ya que no todos buscaban resolver los conflictos vía negociación. Esto quedó claro con la posición contraria a renegociar con los subcontratados de la plana ejecutiva de CODELCO, que pese a las advertencias no varió su postura (La Nación 27/06/2007). Revertir esta posición se transformaría en un escollo importante y un factor de dilatación de la movilización impulsada por los trabajadores.

El desarrollo de la las primeras horas de la huelga tuvo reacciones diversas, especialmente por ocurrir un hecho no planificado por los subcontratados: la quema de buses en la división el Teniente. Los trabajadores movilizados sintieron el hecho como "una liberación colectiva de estrés" y como expresión del heroísmo y fuerza sindical (Peña, 2011). Esto cohesionó internamente al movimiento. Al cual también se le sumó apoyo externo, tal como el dado por el militante socialista y presidente de la CUT, Arturo Martínez, quien también responsabilizó a la plana mayor de CODELCO por no escuchar a los trabajadores e incitar los hechos de violencia (La Nación 25/07/2007).

Pero esta irrupción sorpresiva, fuerte y radicalizada llevó a sobredimensionar la capacidad de movilización de la CTC, que según los periódicos paralizaron 25.000 trabajadores (La Nación 25/07/2007). Sin embargo, eran "once mil, doce mil trabajadores, pero en ningún caso treinta mil. Quien puso ese número fue El Mercurio”, cuestión que los trabajadores no rebatieron, pues les servía, ya que los "presentaba ante los viejos como una organización de treinta mil, que pesa" (Peña, 2011).

Con todo, la disrupción, coordinación y masividad de la huelga movieron el escenario político nacional, instalando a este nuevo actor social, al que le tuvieron que responder discursiva y prácticamente quienes ya eran parte de él. Acompañado de una amplia cobertura a los hechos de violencia, el presidente Ejecutivo de CODELCO, José Pablo Arellano, condenó enérgicamente dichas acciones, resaltando sus costos y anunciando el inicio de procesos legales. Pero también trató de minimizar la fuerza de la movilización, recalcando la normalización de la producción durante la tarde del mismo día 25. Sosteniendo que sólo mantendría canales de negociación con los empleados por división y con quienes se expresaran de forma pacífica (La Nación 26/07/2007).

El vocero de gobierno, Ricardo Lagos Weber, aunque reconocía el derecho a huelga de los trabajadores, respaldó la posición de CODELCO y calificó de vandálicos y delictuales los hechos acaecidos en Rancagua. Terminaba por instarlos a retomar el diálogo y la negociación (La Nación 26/07/2007). Por tanto, la reacción inicial del Ejecutivo demostraba los matices existentes en su interior para manejar el conflicto: si por un lado la cuprífera era dura en condenar los hechos y se negaba a negociar con la CTC, el gobierno apoyaba la idea del diálogo, pero sin precisar con quién. Sin embargo, durante los primeros días de la movilización, más allá de las previsiones señaladas anteriormente, el gobierno no intervino directamente en la política de la cuprífera, debido a que "CODELCO siempre, no solo en este gobierno, tiene un cierto vuelo propio.... y los gobiernos siempre ven a CODELCO como un factor de ingreso. O sea, lo primero importante de CODELCO es 
José Ponce, Oportunidad, conflicto y reconocimiento. El movimiento de trabajadores subcontratados de CODELCO y el Gobierno de Michelle Bachelet, 2006-2007, Izquierdas, 29:106-132

cuanto ingresa a las finanzas fiscales. Así que hay un cierto dejar hacer” (Andrade, 2013). Así, la posición oficial sería la expresada por la plana Ejecutiva de la empresa.

Otros actores sociales se posicionaron rápidamente. La FTC dirigida por Raimundo Espinoza, coincidiendo con las posturas gubernamentales, si bien reconocía y respetaba el derecho a huelga de los trabajadores contratistas, rechazó enérgicamente los actos de violencia ocurridos en el Teniente. Su llamando era a canalizar las denuncias institucionalmente a través de la Dirección del Trabajo, camino que ellos habían seguido con el fin de transparentar la realidad laboral de CODELCO (La Nación 26/ 07/ 2007).

El presidente de la empresarial Sociedad Nacional de Minería, Alfredo Ovalle, también condenó los actos de violencia y enfatizó en que la movilización no solo afectaba a CODELCO, sino que la imagen internacional del país (La Nación 26/ 07/ 2007). Instando a las autoridades "a actuar con apego a las normas legales frente a este tipo de acciones, que afirmó se vienen repitiendo con cierta frecuencia en el país, desvirtuando la naturaleza de las relaciones laborales a través de presiones inapropiadas". Finalmente, llamaba a la cordura y aconsejaba a los trabajadores que este tipo de desmanes los terminaba afectando a ellos mismos (La Nación 26/07/ 2007).

La Iglesia, tal como había hecho en el movimiento de los forestales, si bien criticó los hechos de violencia, interpeló a CODELCO y a las autoridades a dialogar con los trabajadores movilizados (27/06/2007). Era quizás, junto con la CUT, el único actor social relevante que llamó al ejecutivo y la empresa a asumir un rol proactivo en un diálogo a nivel nacional con los trabajadores, objetivo principal de la movilización.

Durante los primeros días de la huelga, los dirigentes de la CTC trataron de sensibilizar a la opinión pública, instalando que la subcontratación en CODELCO era una realidad mayoritaria. Clarificaban que ellos estaban dispuestos al diálogo, pero teniendo como piso mínimo para bajar la huelga la constitución de una mesa de diálogo corporativa, es decir, nacional y no por divisiones, y resolutiva. Dada la respuesta negativa de CODELCO al diálogo en estos términos, culpando a José Pablo Arellano como el principal obstáculo para lograrlo, demandaban la intervención del gobierno (La Nación 27/06/2007).

La notoriedad de la movilización hizo que la propia Presidenta de la República, que aun reiterando el repudio a los actos violentos, instruyera a los ministros a "seguir buscando instancias de diálogo para resolver un problema que, de acuerdo a los trabajadores, no ha sido resuelto adecuadamente" (La Nación 28/06/07). Esto posibilitó que los sectores más abiertos al diálogo en el gobierno tomaran un rol más activo. Osvaldo Andrade afirmaba que: "lo que hemos hecho en concreto, por instrucción de la Presidenta Bachelet, es generar condiciones para que se produzca el diálogo que hace tanta falta en un conflicto de esta naturaleza" (La Nación 29/06/07). Junto con instar a que las empresas contratistas se sumaran al diálogo, trató de generar los puentes para una salida política y negociada al conflicto, antes de que escalaran aún más las tensiones.

Esto contrastaba con la posición del Ministro de Hacienda, quien tomando las mismas palabras de Bachelet, se marginó del conflicto: "la Presidenta, en mi calidad de miembro del directorio de CODELCO, me ha dado instrucciones muy claras, al señalarme que es a la compañía, junto con las empresas contratistas y los trabajadores, a quienes les corresponde buscar soluciones en este problema" (La Nación 29/06/07).

Otro actor que precisó su posición inicial fue Arturo Martínez. Tras la toma de la mina Radomiro Tomic ubicada en las cercanías de Calama, la cual derivó en diferentes hechos violentos, demostrando que "esta(ba)n caldeados los ánimos", comunicándose con 
José Ponce, Oportunidad, conflicto y reconocimiento. El movimiento de trabajadores subcontratados de CODELCO y el Gobierno de Michelle Bachelet, 2006-2007, Izquierdas, 29:106-132

los dirigentes de la CTC para que moderaran sus acciones. Eso sí, no dejaba de criticar a quienes se oponían al diálogo en la cuprífera y el gobierno, culpándolos por no responder a las demandas y de una eventual "situación anormal, como la muerte del trabajador en Arauco", afirmando que "Velasco y Arellano esta(ba)n llevando al país a esta situación. Este conflicto se puede resolver fácilmente si Arellano pone una mesa de conversación, pero ha llevado el conflicto al extremo. La Presidenta tiene que poner mano dura a estos dos muchachos" (La Nación 29/06/07). De tal modo, los sectores de la coalición oficialista, tanto en el gobierno como en el mundo social, proclives a una negociación con los subcontratados emprendían una actitud mucho más activa, incluso criticando a quienes en el Ejecutivo se negaban a ello.

Dichas afirmaciones fueron bien vistas por los trabajadores, pues su objetivo principal era el diálogo, pero para sacudirse de la criminalización inicial de la huelga, denunciaron lo que ellos consideraban "un estado policial represivo tremendo en las cinco divisiones. Tanto el gobierno como CODELCO tienen que empezar a asumir nuestro problema, porque podrían ocurrir hechos más lamentables, como lo que ocurrió en Arauco" (La Nación 28/06/07). Por tanto, denunciaban el "garrote" con el que les respondía CODELCO y su falta de respuesta, para terminar haciendo referencia a la impactante muerte de Rodrigo Cisternas que había remecido al país unas semanas antes.

Los dirigentes del empresariado en la minería privada se desmarcaban del reclamo de los subcontratados por CODELCO y sostenían que "en la minería privada no ha habido reclamos fundamentales" y se estaba aplicando correctamente la Ley de Subcontratación e internalizando trabajadores (La Nación 28/06/07). Con esto buscaban deslegitimar previamente cualquier conflicto de estas características en la minería privada, que tenía algunos síntomas esos días en la huelga de los trabajadores del mineral Santa Inés de Collahuasi. Esto expresaba la agitación potencial que se podía dar si no se resolvía de buena manera el conflicto (La Nación 29/06/07). Por lo que los empresarios encendieron sus alarmas y se reunieron con el Ministro José Antonio Viera-Gallo para hacerle "ver al Gobierno que se esta(ba) propiciando un clima de fuerte presión sindical y que si no se toma(ba)n cartas en el asunto, nadie va a poder parar a estos sindicatos en masa que se están formando. Con esto se está forzando la negociación por sector, porque como este mecanismo no está regulado se busca hacerlo derecho por la fuerza" (La Nación 01/07/2007). Esta lectura del movimiento, hizo que los empresarios enfatizaran en la necesidad de resolver el conflicto a través de los mecanismos legales vigentes, por ende, sin que el gobierno accediera a una negociación corporativa e interempresa. Por ello miraban con suspicacia la pretensión del Ministro Andrade por regular las "nuevas realidades" laborales.

Estas presiones tensionaban a la coalición oficialista. Se reiteraron los reclamos sobre el manejo de Arellano del conflicto (La Nación 01/07/07). Las críticas apuntaron a su incapacidad de neutralizar previamente la movilización y su apelación al gobierno solo para intervenir con la fuerza pública. Era el resurgimiento de las llamadas "dos almas" de la Concertación, cuestión que los subcontratados percibieron: "una más progresista y otra mucho más de derecha... Había un sector que estaba más por una salida política, entre esos estaba Osvaldo Andrade, Belisario Velasco; y otros más duros que eran el Ministro de Hacienda con la gente de CODELCO” (Cuevas, 2011). Esto llegó a tal punto, que un sector 
José Ponce, Oportunidad, conflicto y reconocimiento. El movimiento de trabajadores subcontratados de CODELCO y el Gobierno de Michelle Bachelet, 2006-2007, Izquierdas, 29:106-132

de parlamentarios de la Concertación ${ }^{4}$ presentó un proyecto de reforma constitucional que pretendía fortalecer la negociación colectiva (La Nación 06/07/07). Así, por esos días, los subcontratados sumaban más apoyos y el ambiente político se movía en su favor.

Este marco, llevó a que el 5 de julio se estableciera una mesa de negociación nacional conformada por CODELCO, las empresas Contratistas y la CTC, que avanzó en dos elementos centrales: tarifa nacional de salarios y bonificaciones, y beneficios sociales. (La Nación 03/07/07). Dadas las precarias condiciones orgánicas que tenían los subcontratados, estas conversaciones fueron vistas "como un gran triunfo" para los dirigentes y los trabajadores de base (Peña, 2011). Pero tras días de reuniones y al no llegar a una solución final del conflicto, con el objetivo de presionar, los subcontratados realizan nuevos cortes de ruta a las faenas mineras que terminan en enfrentamientos con carabineros la madrugada del día 10 de julio. Nuevamente el gobierno realza esta situación, exigiendo el rechazo de los actos de violencia por parte de los trabajadores como condición para mantener las conversaciones. La CTC accede a sacar una declaración condenando esos actos como exigía CODELCO (La Nación 10/07/07). Esto se explica porque la concreción de una negociación nacional era un objetivo central para los subcontratados, por lo que mantener la instancia de diálogo era prioritario.

No obstante este gesto, según los subcontratados, de igual forma el día 11 de julio se pospuso una nueva reunión de la mesa de diálogo. Cristián Cuevas lo denunció como una estrategia de José Pablo Arellano, quien le habría mentido al gobierno al informar que sí se habría llevado a cabo la reunión. Por su parte, CODELCO arguiía que habían pospuesto la instancia para ratificar el acuerdo contra los actos de violencia (La Nación 12/07/07). De tal modo, la cuprífera "congelaba" unilateralmente las negociaciones, evidenciándose nuevamente una estrategia de desgaste hacia el movimiento.

El mismo día 11, el presidente de la Confederación de la Producción y el Comercio (CPC) visitó a la presidenta Bachelet y recalcó la posición de los empresarios sobre la convulsionada realidad laboral que enfrentaba CODELCO y el país, precisando también que no estarían dispuestos a participar en una mesa de discusión sobre la negociación colectiva, recalcando que "es una materia que no se debe alterar. Actualmente, el Código del Trabajo nos permite una justa y adecuada negociación con nuestros trabajadores" (La Nación 12/07/07). Así, los empresarios presionaban al gobierno para que CODELCO no continuara con una negociación nacional, deslegitimando cualquier intento por siquiera dialogar sobre las relaciones laborales en el país.

Pero a la movilización los trabajadores le sumaron como mecanismo de presión el apoyo desde sectores de la coalición oficialista hasta la oposición de derecha, entregándole a CODELCO una carta firmada por distintos parlamentarios ${ }^{5}$. Estos actos favorecieron a los trabajadores para reanudar las negociaciones con la estatal, que incluyeron por primera vez la participación de José Pablo Arellano.

El día 14 de julio, CODELCO entregó una primera respuesta a través de Rodrigo Poblete, gerente Corporativo de Abastecimiento de CODELCO, la cual finalmente es desautorizada por la plana ejecutiva (La Nación 17/07/07). Aunque públicamente se afirmaba que el problema era el monto de la bonificación, la dificultad principal era que la

\footnotetext{
${ }^{4}$ Carolina Goic (DC), Sergio Aguiló (PS), Adriana Muñoz (PPD) y Manuel Monsalve (PPD).

5 Igualmente firmaron Adriana Muñoz, Ximena Vidal y René Alinco, del PPD; Carolina Goic y Eduardo Saffirio, por la DC; Julio Dittborn y Felipe Salaberry en representación de la UDI, y el RN Mario Bertolino.
} 
José Ponce, Oportunidad, conflicto y reconocimiento. El movimiento de trabajadores subcontratados de CODELCO y el Gobierno de Michelle Bachelet, 2006-2007, Izquierdas, 29:106-132

cuprífera aún no tenía una salida del conflicto clara, pues si ellos terminaban firmando el acuerdo a nivel nacional, estarían dándoles políticamente el favor a los trabajadores. Esta tensión era causada, como se ha visto, por las dos visiones para resolver la movilización que existían al interior del gobierno, una "controversia bastante polar" sobre si la conversación final incluía o no a CODELCO, materializándose en quien entregaba legalmente el bono. Discusión que sólo se resolvería en la práctica, donde "se fue dando una conversación con un CODELCO presente-ausente, porque tanto el contratista y como el trabajador entendían que para terminar el conflicto la plata la tenía que poder CODELCO" (Andrade, 2013). Pero esto no estaba determinado de antemano, convirtiéndose en un nudo fundamental para destrabar la huelga.

Tras esta situación, la mesa de diálogo se quebraba nuevamente, ante lo que Cuevas respondió en una conferencia de prensa, respaldada por los parlamentarios concertacionistas Sergio Aguiló, Carolina Goic y la presidenta de la comisión de Trabajo de la Cámara de Diputados, Adriana Muñoz. Recalcando que ellos pretendían "reactivar las negociaciones con CODELCO”. (La Nación 17/07/07). Además de ello, realizaron diversas actividades masivas con sus familias en espacios públicos. Así, los subcontratados trataron de manifestar claramente el respaldo político que tenían, consolidando públicamente el apoyo al interior de la Concertación y reavivando su apoyo ciudadano, con la movilizaciones en las zonas céntricas de las ciudades aledañas a los yacimientos mineros.

Aunque por esos días la Presidenta Bachelet se manifestó sobre el tema, recalcando su planteamiento inicial que enfatizaba el diálogo y las movilizaciones pacíficas, al estar en un punto muerto las negociaciones, los trabajadores desarrollaron nuevas tomas, en este caso del yacimiento El Salvador, el cual no pudo iniciar la producción. Arellano mantuvo que la negociación no se repondría hasta deponerse los hechos de fuerza, es decir, se bajara la huelga. Por su parte, Cuevas le endosaba la responsabilidad por los actos de violencia a la dirigencia divisional de CODELCO, la que habría llamado a carabineros a actuar y frenar la movilización (La Nación 18/0707).

El debate llegó a tal punto, que la misma Ley de Subcontratación aprobada hace un año, comenzó a ser criticada, cuestión que el Ministro Andrade trató de neutralizar afirmando que definitivamente el gobierno se restaría de la mediación del conflicto, dejando públicamente a la empresa y los trabajadores como responsables de la solución (La Nación 19/07/07). Es decir, en el momento más tenso del conflicto, el Ejecutivo sale públicamente de las negociaciones y deja sola a la cuprífera para resolver el problema, tratando de minimizar los costos políticos que le podría traer el conflicto al gobierno.

Pero esta postura gubernamental no fue acatada totalmente por los parlamentarios de la coalición oficialista, al contrario, ese mismo día se sumaron otros diputados al respaldo de los subcontratados ${ }^{6}$. Presiones tras las que se restableció la mesa de diálogo (La Nación 19/07/07). Esta situación generó altas expectativas, tanto en los trabajadores como en los ministros del gobierno. Sin embargo, desde CODELCO eran más reticentes las declaraciones (La Nación 20/07/07), sin darle una respuesta satisfactoria a los subcontratados, quienes acusaron a José Pablo Arellano de querer quebrar el movimiento (La Nación 21/07/07). Por esto, algunos trabajadores decidieron quedarse a "alojar" en las dependencias de CODELCO para encontrar una pronta solución. Cristián Cuevas sostuvo que si bien existían avances en los temas de beneficios sociales, "en los temas de fondo que

\footnotetext{
${ }^{6}$ Jaime Mulet (DC), Antonio Leal (PPD), Marco Espinoza (PRSD) y Marco Enríquez-Ominami (PS).
} 
José Ponce, Oportunidad, conflicto y reconocimiento. El movimiento de trabajadores subcontratados de CODELCO y el Gobierno de Michelle Bachelet, 2006-2007, Izquierdas, 29:106-132

tienen que ver con la resolución del conflicto, en las remuneraciones, en los bonos, con los días de huelga y la anulación de los despidos hay una tozudez y de alguna manera una situación de inflexibilidad por parte de CODELCO" (La Nación 21/07/07). Rematando sus declaraciones con un llamado a retomar las movilizaciones.

En ese marco, el gobierno llamó a mantener la calma, porque se estaban buscando soluciones y que los trabajadores se manifestaran dentro del Estado de Derecho (La Nación 21/07/07). Un día después la mesa de diálogo se repuso (La Nación 21/07/07).

Es interesante evidenciar que sólo en este contexto y recién el día 22 de junio se menciona la negociación que CODELCO llevaba paralelamente con el Sindicato Interempresa Nacional de Trabajadores de Montaje Industrial (SINAMI) y otros sindicatos más pequeños de El Teniente, los cuales no eran parte de la CTC (La Nación 22/07/07). Cuestión importante, pues un día después, el 23 de julio, se hizo público el acuerdo logrado por la cuprífera y estas organizaciones. La conferencia se hizo con una alta cobertura mediática, publicitándose como la negociación con todos los trabajadores. Pero la CTC no había llegado a ningún convenio, que además de darle la razón a sus denuncias de prácticas antisindicales por parte de José Pablo Arellano, radicalizaría a los trabajadores.

Se polarizó nuevamente la situación. Por un lado, la CTC sostuvo que no bajaría el paro, llegando incluso algunos trabajadores a declarar una Huelga de Hambre. En base a los hechos antes relatos, Cuevas reiteró su denuncia de que la empresa quería quebrar el movimiento (La Nación 23/07/07). Por su parte, CODELCO afirmaba que la respuesta dada a dichos sindicatos era la última ${ }^{7}$ (La Nación 23/07/07), pero que era extensible a la CTC. Finalmente, a diferencia del discurso que minimizaban las repercusiones de la huelga, utilizado al inicio del conflicto, Arellano señaló que los costos acumulaban más de 40 millones de dólares.

Las tensiones también crecieron al interior de la Concertación. Algunos parlamentarios, encabezados por Sergio Aguiló ${ }^{8}$, amenazaron con realizar una acusación constitucional a Andrés Velasco. Ante este panorama, los presidentes de los partidos de la Concertación fueron enfáticos en rechazar la idea. Igualmente, el gobierno debió salir a despejar dudas y refutar la división al interior de la coalición, afirmando que se había actuado con un solo y mismo criterio: dejar que la empresa resolviera el conflicto (La Nación 23/07/07).

La derecha también sacó la voz. Aprovechando la crisis del oficialismo, su excandidato presidencial, Sebastián Piñera, recalcó las diferencias al interior del gobierno como factor que agudizó el conflicto, bloqueando la solución de lo que calificaba como "una causa justa" (La Nación 23/07/07). Esta declaración, más allá del oportunismo que buscase, evidenciaba que hasta la derecha trataba de construir un discurso que no atacara directamente la movilización. Sin embargo, días después Piñera complementaría que la posición correcta era la impulsada por el Ministro de Hacienda (La Nación 25/07/07).

\footnotetext{
${ }^{7}$ Esta consistía en: "un incentivo de productividad correspondiente al año 2007 de $\$ 450.000$ el que será dividido en dos partes ( 250 mil se entregarán como anticipo y 200 mil terminado el año). El acuerdo compromete además a CODELCO, en su calidad de mandante o empresa principal a establecer en los procesos de licitación y en sus sistemas de gestión, el marco y las condiciones en las que deben darse las relaciones de trabajo de estas y sus trabajadores" (La Nación 23/07/07)

${ }^{8}$ Además de él, en la conferencia estuvieron los diputados vinculados a la Concertación Tucapel Jiménez, Jorge Insunza, Ramón Farías y Patricio Hales.
} 
José Ponce, Oportunidad, conflicto y reconocimiento. El movimiento de trabajadores subcontratados de CODELCO y el Gobierno de Michelle Bachelet, 2006-2007, Izquierdas, 29:106-132

Finalmente, los empresarios de la minería privada apoyaron a la cuprífera, llegando a criticar a las empresas contratistas para ello. Es interesante, como el presidente del Consejo Minero sostuvo que éstas eran las culpables de la agudización del conflicto y que la Estatal había hecho lo posible por resolverlo dentro del marco legal, demostrando su cercanía con los sectores del gobierno contrarios al diálogo, distanciándose tanto de los empresarios contratistas e incluso de la lectura realizada por el liderazgo políticoempresarial de Piñera. Esto porque para la minería privada la inmovilidad de las contratistas provocaba "una negociación fuera del ámbito empleador-empleado, por un mandante que negocia con los trabajadores de sus empresas contratistas" (La Nación 24/07/07). Es decir, los empresarios defendían férreamente el veto a la negociación colectiva interempresa, incluso al costo de inculpar a otros empresarios, alejarse de la posición de la derecha y acercarse a la directiva concertacionista de la empresa estatal.

5) La salida del conflicto: el reconocimiento de los subcontratados y la obstaculización del precedente legal para la negociación ramal.

Con este polarizado telón nacional, los trabajadores redoblaron sus movilizaciones y desataron su "día de furia" el 25 de junio. En el Salvador la producción se mantuvo cortada por las acciones de protesta, mientras que en el Teniente se bloquearon las rutas parando también la producción. El hecho más destacado fue el volcamiento de un tren en la división Andina. A estas acciones se sumó la ocupación por parte de dirigentes de la CUT del ministerio de Hacienda, donde apoyaron a los subcontratados (La Nación 26/07/07).

Pero CODELCO no se dejó doblegar fácilmente, manteniendo su última propuesta y declarando que denunciarían los actos de violencia a la Fiscalía Nacional. Esto fue respaldado por la Bachelet, quien afirmó que "las autoridades de la empresa están haciendo su máximo esfuerzo para resolver ahora el conflicto y espero que lo sigan haciendo con mucha fuerza" (La Nación 26/07/07). La mandataria puso en tensión a los trabajadores mineros al interpelarlos para "que se imponga su sabiduría histórica, que sus reivindicaciones que correspondan por las condiciones salariales del resto de los chilenos y que haya una estricta renuncia a formas de violencia y presión ilegítima" (La Nación 26/07/07). Así, el gobierno trataba de atacar la empatía ciudadana que habían despertado los subcontratados con el resto de trabajadores chilenos, haciendo parecer sus demandas como "privilegios" y no necesariamente como derechos.

Producto de los bloqueos y cortes de rutas, los trabajadores de planta de la estatal suspendieron sus actividades, pidiendo mayor seguridad al Ejecutivo. Esta postura de la dirigencia de la FTC venía a justificar la decisión de CODELCO de aplicar la Ley de Seguridad del Estado a los subcontratados. Raimundo Espinoza negó que estuvieran en contra de las movilizaciones, "pero sí contra los violentistas" (La Nación 27/07/07). De tal modo, Espinoza en su calidad de dirigente sindical e integrante del directorio de la estatal, terminaba siendo útil a la estrategia de CODELCO para desgastar la movilización, pues criminalizaba la acción de los huelguistas e intentaba "bloquear" cualquier potencial solidaridad entre ambos grupos de trabajadores.

Sin embargo, el empresariado que había apoyado el acuerdo de CODELCO, no miraba con buenos ojos que ésta aún apareciera jugando un rol central en la negociación concretada días antes, pues parecía que había cedido a la negociación ramal con los 
José Ponce, Oportunidad, conflicto y reconocimiento. El movimiento de trabajadores subcontratados de CODELCO y el Gobierno de Michelle Bachelet, 2006-2007, Izquierdas, 29:106-132

subcontratados, cuestión que para ellos pasaba a llevar la legislación vigente (La Nación 27/07/07).

Ante esta polarizada situación, la Iglesia jugó un rol activo creciente para mediar el conflicto, dado que el gobierno se había restado oficialmente. Fue el Cardenal Francisco Javier Errázuriz quien interpeló a CODELCO y a las empresas estatales a dar un ejemplo en "equidad", apoyando la solución del conflicto propuesta por los trabajadores. De allí que la Conferencia Episcopal de Chile, si bien criticó por "inequitativa" e "injusta" a la subcontratación, no cuestionó la Ley de Subcontratación. Esto llevó a la Iglesia a tener un discurso comprensivo pero no legitimante de la violencia, pues según su lectura, ésta era "el síntoma de una situación de inequidad evidente que no ha sido resuelta por nuestra sociedad". Llamó a empresarios, trabajadores, autoridades y legisladores "para que aborden estas situaciones con espíritu de concordia". Declaraciones recibidas con satisfacción por la CTC y la CUT (La Nación 26/07/07), ya que apuntaban a reiniciar las negociaciones.

Por otro lado, algunos sectores seguían presionando en el seno de la coalición oficialista. El presidente de la CUT demandó a la Presidenta jugar un rol más relevante y resolver un tema que ya no era puramente económico, sino que político (La Nación 27/07/07). Igualmente, presionaron los parlamentarios 99 que venían criticando el rol de Velasco y Arellano. Sus objeciones subieron de calibre, adjudicándole a estos últimos de "utilizar las mismas prácticas antisindicales de la dictadura, amenazando y dividiendo al movimiento sindical", calificándolos como "neoliberales de pura cepa", preocupados de los indicadores y por no conocer "la realidad social de Chile, son ajenos a las luchas de nuestros trabajadores y no tienen la sensibilidad social para acoger las demandas y preocupaciones de los sectores excluidos por el modelo económico", siendo quienes "arriesgan [al] gobierno a enfrentamientos fratricidas". Sumándose al llamado de los trabajadores, aconsejaban a la Presidenta tomar una decisión y aceptar el diálogo (La Nación 27/07/07). Esto reflejaba el nivel de tensión alcanzado en el oficialismo.

En este marco, Raimundo Espinoza se convertía en un "ariete" de CODELCO, al disparar contra la CTC, afirmando que se había "instrumentalizado ideológicamente el conflicto" por el Partido Comunista. Ante esto, Lautaro Carmona respondió duramente, encarando al presidente de la FTC, por su condición de director de la cuprífera, acusándolo de "descalificar y dividir al movimiento sindical". En el mismo tono, declaró Cristián Cuevas, señalando que Espinoza carecía de independencia con respecto a la empresa por su rol en el directorio (La Nación 28/07/07). Desmarcándose de las declaraciones de Espinoza, el gobierno sostuvo que "sería muy reductivo pensar que hay un partido que puede manejar todo el movimiento" (La Nación 28/07/07).

Ante este altamente crispado ambiente, la Iglesia se transforma en el único actor capaz de mediar públicamente el conflicto. Efectivamente, en un marco donde ninguna de las partes quería ceder, se buscó al Obispo Alejandro Goic como articulador de un diálogo. De allí que el día 30 de julio, en Rancagua, con "el afán de facilitar el acercamiento y el diálogo entre las partes", la Iglesia abrió sus puertas para "buscar las vías de arreglo", pidiéndoles a todos "mayor generosidad para avanzar hacia el encuentro de posiciones". Contexto en que representantes de CODELCO y los dirigentes nacionales de la CTC

\footnotetext{
${ }^{9}$ La declaración es suscrita por los diputados socialistas Sergio Aguiló y Marco Enríquez-Ominami, los DC Jaime Mulet, Pedro Araya, Alejandra Sepúlveda, Carlos Olivares y Carolina Goic, y los PPD René Alinco y Tucapel Jiménez.
} 
José Ponce, Oportunidad, conflicto y reconocimiento. El movimiento de trabajadores subcontratados de CODELCO y el Gobierno de Michelle Bachelet, 2006-2007, Izquierdas, 29:106-132

construyeron "una propuesta final destinada a poner fin a la huelga, propuesta alcanzada en el marco de sus conversaciones facilitadas por la Iglesia". Si bien reconocían que las demandas laborales originales no se cumplían en su totalidad, el prelado llamaba "a los trabajadores [a] reiniciar sus actividades laborales a la mayor brevedad, y a las empresas a promover relaciones normales de diálogo con sus trabajadores" (La Nación 30/07/07). Rápidamente, tanto el gobierno como José Pablo Arellano -sin haber participado de esta negociación-, declaraban que "hemos llegado a un punto donde las diferencias se han resuelto", reconociendo el rol de Goic para destrabar el conflicto (La Nación 31/07/07).

Este papel jugado por la Iglesia para resolver el conflicto fue bastante relevante para el Ejecutivo, ya que le permitió dejar a un actor social ocupando públicamente un rol que los trabajadores reclamaban para el gobierno. Con ello, no tuvo que ceder en la decisión de restarse de la mediación, operando tras bambalinas. La relación entre ambos fue descrita así: "a mí como ministerio del trabajo me interesaba, le ponía una dosis externa de solidarización [sic] con los propios trabajadores. Tanto así que yo fui a Rancagua y nos pusimos un poquito de acuerdo respecto a qué cosas decía él. Ahí hubo una complicidad muy interesante" (Andrade, 2013). Aunque, las intervenciones de la Iglesia no eran completamente bien vistas por el gobierno, probablemente en esa instancia Andrade le haya pedido al prelado que llamara a un diálogo y abriera las puertas para destrabar un conflicto donde la forma pública de su resolución era fundamental. De esta manera, CODELCO no tenía que llamar a los trabajadores a volver a negociar. Creemos que este formato de salida se fue gestando días antes de la negociación final, cuando se reunieron Goic y Andrade (La Nación 25/07/2007).

Pero dicho acuerdo debía ser ratificado por las bases en las asambleas de la CTC. Mientras tanto, El Teniente reiniciaba su producción, los dirigentes de la CTC orientaron a sus trabajadores a apoyar el acuerdo, arguyendo que había sido una propuesta construida con su participación. El Acuerdo Marco firmado integró las siguientes mejoras laborales: reajuste salarial equivalente a la variación semestral del IPC; pago de horas extraordinarias; indemnización por años de servicio proporcionales para aquellos trabajadores cuyo contrato haya tenido una vigencia entre 4 meses y un año; seguro de muerte accidental e invalidez total; seguro complementario de salud para el trabajador y sus cargas familiares; y un bono de productividad de $\$ 450.000$ (CODELCO-CTC, 2007).

Más allá de los logros económicos, su énfasis discursivo estuvo puesto en "la gran victoria" de haber negociado "con la empresa principal e instalar en Chile en los hechos junto con las partes y mañana en derecho la negociación ramal y sectorial" (La Nación 31/07/07). Si bien esta no era una negociación de este tipo en estricto rigor, ni en los hechos ni en el derecho, pues no incluía al conjunto de los trabajadores de la minería cuprífera, ya que no estaban ni los del área privada ni los de planta de CODELCO, si era un acuerdo nacional y corporativo de la principal empresa del país con una Confederación de trabajadores, ambos elementos negados por la ley. De tal modo, el gran logro de los subcontratados el 2007 fue desbordar la ley, realizar una negociación interempresa directamente con la mandante, que no era nada menos que la principal empresa del país y en la industria más importante del esquema productivo nacional.

A su vez, José Pablo Arellano quedó satisfecho tras la ratificación, enfatizando que "cuando se dialogó se lograron buenos resultados, se lograron puntos de acuerdo y el acuerdo que han suscrito hoy todos los trabajadores. Por lo tanto si algún precedente o alguna lección podríamos sacar [es que] el diálogo es el camino para llegar a un buen 
resultado", sin dejar de reiterar su crítica a los hechos de violencia desarrollados durante la huelga (La Nación 31/07/07). De igual modo, tratando de bajarle el perfil, otro ejecutivo de CODELCO rechazó hablar de victoria dadas las pérdidas materiales y económicas vividas durante la huelga. (La Nación 1/08/07).

Se debe precisar que, finalmente, el Acuerdo Marco responde a una estrategia de resolución de conflictos que minimizó los costos políticos para CODELCO en el mediano plazo, ya que la firma final de la estatal quedaba sólo como garantía del compromiso, que legalmente eran dadas por las empresas contratistas a los sindicatos articulados a la CTC. Por ello, Andrade nos relata que

para no formalizar una mesa de negociadora con CODELCO instalada, que pudiera tener precedentes para futuro, se buscó en la práctica -y ahí CODELCO tuvo sapiencia- generar un espacio de conversación, en que los trabajadores entendían estaban negociando con CODELCO, pero entendía que para llegar allá, la conversación era con un intermediario que eran los contratistas" (Andrade 2013).

Es decir, aunque en el corto plazo CODELCO negoció y cedió a una negociación corporativa-nacional a la CTC, el documento legal finalmente quedaba dentro de los marcos de una negociación entre las empresas contratistas y sus trabajadores, sólo respaldada por la estatal. Así, creemos que CODELCO diluyó un posible precedente legal que pudiera ser rescatado política y jurídicamente para la negociación sectorial como pretendían los trabajadores.

Dada esta resolución del conflicto, el Ministro del Trabajo debió reunirse con el presidente de la CPC para clarificar la posición del gobierno en materia laboral. Andrade precisó que la mesa de trabajo sobre el tema que llamaría el ejecutivo buscaría aclarar algunas cosas en la perspectiva de mejorar elementos de la negociación colectiva (La Nación 01/08/07). De allí que diversos representantes del empresariado calificaran como una "amenaza" lo ocurrido en la cuprífera (La Nación 2/08/07).

Los parlamentarios oficialistas que apoyaron a los trabajadores quedaron satisfechos, aunque sin dejar de criticar al directorio de CODELCO, y catalogaron como pionera la movilización para allanar el camino a una negociación por rama. Mientras que la derecha destacó que el movimiento demostraba el pésimo rol como empleador del Estado, que en vez de generar más productividad la empresa pública, estaba creando más precariedad (La Nación 02/08/07).

Sin duda que uno de los más reconocidos políticamente fue el Obispo Goic. Su intervención final puso su opinión en el centro del debate, que gracias a la acción de los trabajadores aprovechó de instalar su preocupación sobre la desigual distribución del ingreso en el país, relevando una concepción ética y no puramente económica de este fenómeno, proponiendo la necesidad de un "sueldo ético" (La Nación 02/08/07). Ante esto, la Presidenta Bachelet llamó a la conformación del Consejo Asesor para la Equidad Social que discutiera diversos temas laborales, salariales y sindicales.

Las tensiones de los días posteriores a la negociación siguieron en torno a los despidos en el marco de la huelga. Finalmente, tras presiones de la CTC, CODELCO se comprometió para dejar sin efecto despidos injustificados (La Nación 03/08/07). 
José Ponce, Oportunidad, conflicto y reconocimiento. El movimiento de trabajadores subcontratados de CODELCO y el Gobierno de Michelle Bachelet, 2006-2007, Izquierdas, 29:106-132

\section{Conclusiones}

La carencia de análisis sobre el movimiento de subcontratados de CODELCO del año 2007 que se preocuparan de circunscribir históricamente y que pusieran en diálogo a este movimiento con otros actores, impulsó esta investigación. Su transformación en un movimiento social que desbordó una acción colectiva coyuntural, permitió mirar este acontecimiento desde la teoría de las estructuras de oportunidades políticas. Desde este enfoque, consideramos que los planteamientos sostenidos en el apartado introductorio, se demostraron en el resto de la exposición.

En tal sentido, la experiencia de lucha, la fuerza aglutinada y organizada hacia el 2006-2007, les permitió a los subcontratados utilizar en su favor una estructura de oportunidades políticas coyunturalmente favorable. Los desplazamientos y nuevos equilibrios entre las fuerzas políticas institucionales, tanto por las disputas gobiernoderecha como en el seno de la coalición oficialista. Estos se sumaron al "boom" histórico del cobre y el debate sobre el aporte del "metal rojo" al país, pero que dada la precarización laboral de sus trabajadores, hacía que estos la vivieran de forma más contrastable de lo que se daba en otros sectores del espacio laboral chileno. Los subcontratados, organizados nacionalmente en la CTC, usaron las divergencias al interior del gobierno, tendiendo redes y lazos para presionar al Ejecutivo y al directorio de CODELCO, mientras intentaban sensibilizar a la opinión pública de la justicia de sus demandas, más cuando eran parte de la industria más importante del país. Eso sí, no se debe negar que esta estructura de oportunidades políticas que aprovecharon los subcontratados, al mirarse globalmente dichos factores, fue bastante excepcional: pues no todos los trabajadores producen en la principal industria del país, en una empresa estatal que le otorga importantes ingresos al fisco, en un empresa distribuida en varias regiones del país y en el marco de una sensible opinión pública sobre lo laboral, entre otros factores analizados. No obstante esta particularidad, e incluso cuando la dinámica del conflicto evidenció los límites de la fuerza obrera, el ímpetu, voluntad y sentido de oportunidad histórica de los subcontratados del cobre, les permitió usar en favor de sus demandas dicho contexto, logrando una de sus principales demanda: ser reconocidos política y laboralmente por la empresa más grande del país, como lo es CODELCO.

Ahora bien, aunque los subcontratados pudieron resolver algunos de sus más agudos problemas de precarización laboral, no ocurrió lo mismo con otros objetivos de largo plazo que buscaban, como era sentar un precedente legal de negociación sectorial en el país. Su triunfo en el corto plazo, especialmente la negociación interempresa y corporativa con la mandante, no pudo dinamizar en una magnitud mayor al movimiento sindical chileno y fortalecer una lucha por la negociación "ramal", pues no transformaron esta situación de facto en un antecedente que fuera usado posteriormente de forma política y jurídica por los demás sectores sindicales, como pretendían los subcontratados.

A su vez, los partidos políticos y el sistema institucional fue tensionado por el conflicto analizado. Las estrategias de concertación social que neutralizó al sindicalismo durante un extenso periodo de la "transición", debieron ser reformuladas para tomar en cuenta a este nuevo actor laboral. Las formas sobre cómo neutralizar a estos trabajadores al calor de la movilización desatada, devino en conflictos internos en la coalición gobernante, pero será materia de otras investigaciones ver en qué medida los partidos y los gobiernos 
José Ponce, Oportunidad, conflicto y reconocimiento. El movimiento de trabajadores subcontratados de CODELCO y el Gobierno de Michelle Bachelet, 2006-2007, Izquierdas, 29:106-132

han trazado nuevas estrategias para controlar al sindicalismo subcontratados dentro de ciertos márgenes.

Esta y otras investigaciones recientes evidencian un positivo pero incipiente abordaje desde la historiografía a la acción sindical en la posdictadura. Si bien en otras instancias hemos integrado dimensiones más complejas de este caso (Ponce, 2016), estos estudios todavía están lejos de acotar y cerrar el tema sobre el movimiento subcontratado de CODELCO. Particularmente un tema nos surge como una arista clave a la luz de esta investigación: la relación entre partidos políticos y movimientos sindicales. Pues, como hemos visto tangencialmente, esta dimensión parece mantenerse en el seno de la acción sindical, especialmente en los conflictos más intensos, cuestión que paradojalmente no ha sido abordado en profundidad. Aunque esto no solo con respecto al reciente de Chile, sino que para toda la historia del país, pues salvo un trabajo de Alan Angell (1974), no existen más trabajos monográficos al respecto. En esta investigación pudimos ver cómo algunos aspectos de esta vinculación operaron en beneficio de los trabajadores, contradiciendo aquellos planteamientos que ven los lazos de los movimientos sindicales con los partidos políticos como una situación nociva. Precisar las relaciones con algunos partidos o ampliarlas hacia otros actores, será también materia de otras investigaciones.

Integrar variantes políticas como las referenciadas aquí, pueden ser fundamentales para dar cuenta del desarrollo del movimiento sindical en la posdictadura desde una óptica más compleja. En efecto, si la irrupción de los subcontratados llevó a que algunos autores propusieran que estaba emergiendo un "nuevo movimiento sindical", también hubieron otras voces que al ver similitudes con la acción obrera del pasado hablaron del "renacer de la huelga obrera". Dar cuenta de una serie de variables sociales, culturales y, por sobretodo, políticas del sindicalismo en la posdictadura, puede ayudar a caracterizar como un mosaico las distintas realidades de las organizaciones de trabajadores en el Chile reciente. En este sentido, los análisis sobre las prácticas políticas concretas son variables claves para hacer un balance sobre el sindicalismo. En esta lógica, creemos que conceptos provenientes de las otras ciencias sociales, como el de estructura de oportunidades políticas, con su debida utilización en perspectiva histórica, pueden servir para dar cuenta de estos fenómenos. Acá hemos realizado un pequeño aporte en torno a un tema sumamente difícil de desentrañar, que otras investigaciones podrán problematizar, esperamos, de mejor manera.

Bibliografía.

- AGACINO, Rafael (2001), "El capitalismo chileno y los derechos de los trabajadores" en Cuadernos de Trabajo, Universidad Veracruzana. Disponible en: http://www.uv.mx/iihs/files/2012/11/Cuaderno9.pdf

- AGUIAR, Sergio (2011), "La clase trabajadora en los gobiernos de la Concertación. El ciclo de la hegemonía/dominio de la burguesía y la colaboración de clases: de la subordinación a la crisis de la subordinación", en Cuadernos de Estudios del Trabajo, $\mathrm{n}^{\circ}$ 22. Disponible en: www.estudiosdeltrabajo.cl

- ÁllVAREZ, Rolando (2009), “¿Desde fuera o dentro de la institucionalidad? La "Huelga larda del salmón" y las nuevas estrategias sindicales en Chile (2006-2008)", en Antonio Aravena y Daniel Núñez (ed). El renacer de la huelga obrera en Chile, ICAL, Santiago.

- AMTMANN, Carla, BARRERA, Esteban y SERRA, María (2011), Revirtiendo la derrota histórica del sindicalismo. La conformación de la Confederación de Trabajadores del 
José Ponce, Oportunidad, conflicto y reconocimiento. El movimiento de trabajadores subcontratados de CODELCO y el Gobierno de Michelle Bachelet, 2006-2007, Izquierdas, 29:106-132

Cobre y la Gran Huelga del año 2007. Tesis para optar al título de Licenciado en Educación, Universidad Católica de Valparaíso, Chile.

- ANGELl, Alan (1974), Partidos Políticos y Movimiento Obrero. Desde los orígenes hasta el triunfo de la Unidad Popular, Ediciones ERA, México.

- ARAVENA, Antonio y NÚÑEZ Daniel (ed) (2009), El renacer de la huelga obrera en Chile. ICAL, Santiago.

- ARAVENA, Antonio y NÚÑEZ, Daniel (2011), "Los Gobiernos de la Concertación y el Sindicalismo en Chile" en Revista Trabajo, Centro de Análisis del Trabajo, UAMIztapalapa, Año 5, $\mathrm{N}^{\circ}$ 8, OIT, México. pp. 113-130. Disponible en: http://www.izt.uam.mx/sotraem/Documentos/Trabajoa5n82011.pdf

- CASTILLO, Luis (2011), La experiencia de precarización laboral y formación identitaria de los trabajadores subcontratistas de Codelco, raíces del conflicto 2006-2008. Tesis para optar al grado de Magister en Historia, Universidad de Chile. Disponible en: http://www.tesis.uchile.cl/tesis/uchile/2011/fi-castillo 1/html/index-frames.html

- CÓRDOVA, Lorena (2005), Relaciones Laborales y el Proceso de Reformas Laborales. Tesis para optar al grado de Magister en Ciencias Sociales, Universidad de Chile. Disponible en: http://www.tesis.uchile.cl/tesis/uchile/2005/cordova_1/sources/cordova_1.pdf

- DRAKE, Paul (2003), "El movimiento obrero en Chile: De la Unidad Popular a la Concertación" en Revista de Ciencia Política, Volume XXIII, n 2, pp. 148-158. Disponible en: http://www.scielo.cl/pdf/revcipol/v23n2/art07.pdf

- DE LA MAZA, Gonzalo (1999), "Los movimientos sociales en la democratización de Chile" en Paul Drake e Ivan Jaksic, El modelo Chileno. Democracia y Desarrollo en los noventa. Lom Ediciones, Santiago. pp. 377-406

- ECHEVERRÍA, Magdalena (2010), La historia inconclusa de la subcontratación y el relato de los trabajadores, Santiago, División de Estudios, Dirección del Trabajo. Disponible en: http://www.dt.gob.cl/documentacion/1612/articles-97627 recurso 1.pdf

- FAZIO, Hugo y PARADA, Magaly (2010), Veinte años de política económica de la Concertación, Lom-ediciones. Santiago, Chile

- FERRES, María (2009), "Progresismo y movimiento sindical en Chile" en Yesko Quiroga y Jaime Ensigna (ed.), Chile en la Concertación (1990-2010). Una mirada crítica, balance y perspectivas. Friedrich Ebert Stiftung, Santiago. Disponible en: http://www.chile21.cl/wpcontent/uploads/2012/08/Chile-en-la-Concertaci\%C3\%B3n-1990-2010.-Una-miradacr\%C3\%ADtica-balance-y-perspectivas.pdf

- FIGUEROA, Rodrigo (2008), "Regulación de la subcontratación y el suministro de trabajadores en Chile" en Veredas, UAM-Xochimilco, México, pp. 129-152. Disponible en: http://148.206.107.15/biblioteca_digital/articulos/12-318-4967akf.pdf

- FRÍAS, Patricio (2008), Desafíos del Sindicalismo en los inicios del siglo XXI. Clacso-OITUniversidad Central, Santiago. Disponible http://bibliotecavirtual.clacso.org.ar/ar/libros/coedicion/frias/FRIAS.pdf

- HENRÍQUEZ, Helia (1999), "Las relaciones laborales en Chile: ¿Un sistema colectivo o un amplio espacio para la dispersión?" en Paul Drake e Ivan Jaksic, El modelo Chileno. Democracia y Desarrollo en los noventa. Lom Ediciones, Santiago, pp. 93- 122.

- JORDANA, Claudia y TORRES, Juana (2009), "Los trabajadores subcontratistas de Bosques Arauco y CODELCO: ¿Un movimiento en vías de politización?” en Revista MAD. Universidad de Chile. $\mathrm{N}^{\circ}$ 20, Mayo, pp. 71-89. Disponible en: http://www.revistamad.uchile.cl/index.php/RMAD/article/viewArticle/13795/14076

- JORDANA, Claudia y TORRES, Juana (2013), "El movimiento de trabajadores subcontratistas de CODELCO-Chile (2006-2008)". Ponencia presentada al VII Congreso 
Latinoamericano de Sociología del Trabajo. Disponible en: http://congressoalast.com/wpcontent/uploads/2013/08/241.pdf

- LATORRE, Hugo (2005), "La entrega incondicional del cobre", en Gabriel Salazar y otros Gobierno de Lagos: balance crítico, Lom Ediciones, Santiago. pp. 29-42

- LEIVA, Sandra (2009), "La subcontratación en la minería en Chile: elementos teóricos para el análisis", Polis, Universidad Bolivariana, Volumen 8, n² 24, Santiago, pp. 111-131. Disponible en: http://www.scielo.cl/pdf/polis/v8n24/art07.pdf

- LORCA, Claudio y NÚÑEZ, Pedro (2012), El desarrollo de la Gran Minería del Cobre en Chile. La política adoptada en los gobiernos de la Concertación (1990-2010), Tesis para optar a los grados de Licenciado en Historia y en Educación, Universidad de Valparaíso, Chile.

- LÓPEZ, Diego (2009), El movimiento sindical en el gobierno de Michelle Bachelet: nuevas acciones y liderazgos. Friederich Ebert Stiftung. Disponible en : www.fes.cl

- NÚÑ̃EZ, Daniel (2009), "El movimiento de los trabajadores contratistas de CODELCO: Una experiencia innovadora de negociación colectiva" en Antonio Aravena y Daniel Núñez (ed). El renacer de la huelga obrera en Chile, ICAL, Santiago.

- PONCE, José (2016), “Acción sindical durante los gobiernos de la Concertación. Los casos de las movilizaciones de Lota (1994-1997) y de Codelco (2005-2008)", Tesis para optar al grado de Magister en Historia, Universidad de Santiago de Chile.

- SILVA, Consuelo (2009), "La Subcontratación en Chile: aproximación sectorial". Consejo Asesor presidencial Trabajo y equidad, Santiago, Chile. Disponible en: http://www.estudiosdeltrabajo.cl/wp-content/uploads/2008/11/la-subcontratacion-en-chilec1-silva.pdf

- TARROW, Sidney (1997), El poder en movimiento. Los movimientos sociales, la acción colectiva y la política, Alianza, Madrid.

- TOLEDO, César (2009), "La subcontratación laboral en Chile. Análisis de la Ley $\mathrm{N}^{\circ}$ 20.123”. Revista Laboral Chilena. 우 177. Junio, (76-82).

- UGARTE, José (2006), "Sobre relaciones laborales triangulares: la subcontratación y el suministro de trabajadores", Ius et Praxis. Universidad de Talco, Facultad de Ciencias Jurídicas y Sociales. Año 12, $\mathrm{N}^{\circ}$ 1. Talca, Chile. Disponible en: http://www.scielo.cl/scielo.php?script=sci $\operatorname{arttext\& pid=S0718-~}$ 00122006000100002\&lng=es\&nrm=iso\&tlng=es

- VILLALOBOS, Cristóbal (2010), "Subcontratación y sindicalismo en el siglo XXI: Relaciones sociales, Trabajo y Organización Sindical en la gran minería del cobre chileno". Revista GPT, Universidad de Santiago, Chile, $\mathrm{N}^{\circ}$ 8, Agosto. Disponible en: http://www.revistas.usach.cl/ojs/index.php/revistagpt/article/viewFile/649/613

- WOMACK, John (2007). Posición estratégica y fuerza obrera. Fondo de Cultura Económica, México.

Entrevistas:

- CUEVAS, Cristian (2011)

- AHUMADA, Manuel (2011)

- PEÑA, Jorge (2011)

- VÉLIZ, Jedry (2011)

- ANDRADE, Osvaldo (2013)

Fuentes:

- $\quad$ La Nación, Junio-Agosto, 2007. 
José Ponce, Oportunidad, conflicto y reconocimiento. El movimiento de trabajadores subcontratados de CODELCO y el Gobierno de Michelle Bachelet, 2006-2007, Izquierdas, 29:106-132

- CODELCO-CTC (2007), Acuerdo Marco.

- Observatorio Social de América Latina (Osal), Enero 2003-Diciembre 2008.

- Comisión Chilena del Cobre. Disponible en: http://www.cochilco.cl/ 